\title{
The Body Surface as a Communication System: The State of the Art after 50 Years
}

\section{Abstract}

The suggestion that the body surface might be used as an additional means of presenting information to human-machine operators has been around in the literature for nearly 50 years. Although recent technological advances have made the possibility of using the body as a receptive surface much more realistic, the fundamental limitations on the human information processing of tactile stimuli presented across the body surface are, however, still largely unknown. This literature review provides an overview of studies that have attempted to use vibrotactile interfaces to convey information to human operators. The importance of investigating any possible central cognitive limitations (i.e., rather than the peripheral limitations, such as related to sensory masking, that were typically addressed in earlier research) on tactile processing for the most effective design of body interfaces is highlighted. The applicability of the constraints emerging from studies of tactile processing under conditions of unisensory (i.e., purely tactile) stimulus presentation, to more ecologically valid conditions of multisensory stimulation, is also discussed. Finally, the results obtained from recent studies of tactile information processing under conditions of multisensory stimulation are described, and their implications for haptic/tactile interface design elucidated.

The failure to explore the entire body for locus as a codable cue is not the result of neglect, nor yet of lack of interest in the outcome. In this electronic age so many things have to await technological advance. We simply have not had a transducer with the right property to make the experiment feasible.

F. A. Geldard, 1960.

\section{Introduction}

We chose to begin this paper with a quote from one of the first and foremost researchers to have system-

Presence, Vol. 16, No. 6, December 2007, 655-676 (c) 2007 by the Massachusetts Institute of Technology atically approached the problem of cutaneous communication using the body surface. The quote, dating from 1960, and the paper from which the quote was taken, nicely highlight the novel interest in the topic as well as the technological constraints limiting the study of tactile information processing across the body at the time that Frank Geldard was writing. What's more, the choice of the date for such a citation is by no means accidental, given that in 1960 a group of investigators conferred at Fort Knox, Kentucky in order to discuss the basic problems associated with any attempt to communicate through the skin (see Hawkes, 1960, for a summary of the papers presented at that symposium). Therefore, we believe that $1960 \mathrm{can}$, in some sense, be taken to represent the "symbolic" birth of the first extensive research in this field. The place of the meeting was by no means coincidental either, given the strategic importance at that time (and even today), of studying novel means of communication for both military and civilian purposes.

Nearly 50 years later, technology has moved on a long way, and a new wave of interest has recently started to resurface regarding the theoretical and practical ad-

\section{Alberto Gallace* \\ Crossmodal Research Laboratory \\ Department of Experimental Psychology \\ Oxford University \\ Oxford, OXI 3UD, UK}

\section{Hong Z. Tan}

Haptic Interface Research Laboratory

Purdue University

West Lafayette, IN 47909

\section{Charles Spence}

Crossmodal Research Laboratory

Department of Experimental Psychology

Oxford University

Oxford, OXI 3UD, UK

*Correspondence to alberto.gallace@unimib.it. 
vantages of developing a better understanding of the limitations in terms of tactile information processing across the body surface. Indeed, the last few years have seen a very rapid growth of interest in the development and utilization of tactile interfaces in a variety of applied settings (e.g., Brown, Brewster, \& Purchase, 2006a; Brown \& Kaaresoja, 2006; Burnett \& Porter, 2001; Castle \& Dobbins, 2004; Ho, Tan, \& Spence, 2005; Marks, 2006; Sorkin, 1987; Tan \& Pentland, 2001; Van Erp, 2000; Van Erp \& Van Veen, 2003; Van Erp, Van Veen, Jansen, \& Dobbins, 2005). This interest has, in part, been generated by the widespread belief that the body surface might offer an important (but, at present, relatively underutilized) means of presenting information to interface operators in situations where their other senses either cannot be used, or else, as is more often the case, may already be overloaded (e.g., Deatherage, 1972; Geldard, 1960; Ho \& Spence, 2006; Sanders \& McCormick, 1987; Sorkin, 1987; Spence \& Driver, 1997; Van Veen \& Van Erp, 2000; Weisenberger \& Miller, 1987).

Although researchers have been discussing the possibility of transmitting information to human operators using tactile displays for nearly half a century (e.g., see Craig \& Sherrick, 1982; Deatherage, 1972; Geldard, 1960; R. H. Gibson, 1963; Hennessy, 1966; Levison, Tanner, \& Triggs, 1973; Von Haller Gilmer, 1960, 1961), it is only recently that the technology in this area has really developed to a sufficient degree to make this a very practical possibility (e.g., see Benali-Khoudja, Hafez, Alexandre, \& Kheddar, 2004, for a more recent review). A large portion of the early studies tended to focus their attention on the possibilities and limitations associated with "electrocutaneous" forms of bodilycommunication with stimulators (electrodes) placed directly on the skin surface (e.g., Geldard, 1960). However, many of the earlier studies as well as the majority of more recent studies have tended to focus on trying to identify the limitations associated with the use of "vibrotactile" stimulation (with tactors that can be placed over the top of an interface operator's normal clothing), given the realization that pneumatic, electrocutaneous, and other types of tactile stimulation systems have limited use in the majority of practical settings (though see
Kajimoto, Kawakami, Tachi, \& Inami, 2004; Sampaio, Maris, \& Bach-y-Rita, 2001; Tang \& Beebe, 2003, for recent attempts to use electrocutaneous stimulation to present information to human operators). Therefore, we thought it important to examine the state-of-the-art in terms of current research regarding vibrotactile information processing across the body surface with one eye on the past and the other on the future development of such technologies/interfaces.

The importance of reviewing the available literature on tactile processing across the body is also highlighted by two specific observations. 1) It has recently been suggested that the majority of commercial vehicles will be fitted with some kind of vibrotactile stimulation device by 2020 (Denso Corporation, Japan, personal communication, September 10, 2004). Refer to Smith, 2004, for a recent article concerning one of the first examples of vibrotactile cues being used to alert potentially sleepy drivers in commercial vehicles. Also interesting is the "Lane departure warning system" developed by Citroen, that informs the car driver of any unintended line crossing by vibrating one side of the driver's seat (Times OnLine, 09 January 2005). More recently, the “Touchy Feely Screen" developed by Immersion Corporation, CA, is currently being licensed to automakers, display manufacturers, and other companies (2005).

2) The first prototypes of body-suit vibrotactile displays for virtual reality applications have recently been developed and are now being formally tested (see Lindeman, Page, Yanagida, \& Sibert, 2004; Yano, Ogi, \& Hirose, 1998).

Therefore, the possibility of a future in which the body surface is successfully used as a communication device now appears to be more likely than ever before (see Lindeman et al., 2004; Yano et al., 1998). Note, however, that the great excitement and interest associated with using tactile stimulation to present complex information to humans (even the idea of a completely new tactile language "vibratese" has been proposed; see Geldard, 1960; see also Hennessy, 1966; Sherrick, 1985; von Haller Gilmer, 1961), and the large amount of human and financial resources that have been devoted to achieving this goal since the 1960s, have not actually given rise to the tangible improvements in tac- 
tile communication that were promised all those years ago. This surprising lack of applied success might, in part, we believe, be related to the fundamental failure of early research to consider the central/cognitive as well as the peripheral limitations that may constrain tactile information processing across the body surface. (It is, though, perhaps worth noting that the majority of early research in this area was directed toward the development of sensory substitution systems for visually and hearing impaired individuals, rather than to the design of human-operator communication devices for fully enabled individuals). A similar problem has also beset much of the more contemporary research. For example, the iDrive system, co-developed by Immersion Corporation and $\mathrm{BMW}$, provides one recent example of a well-engineered interface that, we would argue, simply demands too many cognitive resources from its userthe driver.

Therefore, given that technology has now moved on, one of the principle aims of the current review is to stress the importance of studying the central/cognitive aspects of tactile communication, in order to build upon our knowledge of the peripheral limitations in tactile information processing already established by earlier research. It should always be borne in mind that technological advances by themselves will not lead to the design of particularly effective and usable tactile interfaces for human-machine operators, without the support provided by the concurrent study of the limitations constraining human information processing! That is, optimal haptic/tactile interfaces require that the technological innovations match the human operator's sensory information processing capacities.

In this review, early studies in which the sensory limitations on tactile information processing were first described will be compared to more recent studies in which some of the more central (i.e., as opposed to peripheral) limitations on tactile information processing are only now beginning to be studied. We are particularly interested in the fundamental limitations on the types of tactile stimulation patterns that can be effectively used in a wide variety of applications such as automobile collision warning systems for drivers, the enhancement of the sense of "presence" in virtual reality settings, and the development of situation awareness displays for astronauts. The new advances in multisensory research and their relevance to identifying the limits in tactile information processing across the body will also be discussed.

\section{Tactile Processing across the Body Surface}

Although researchers have, for many years, been interested in the potential use of tactile displays to present information to interface operators (e.g., Deatherage, 1972; Geldard \& Sherrick, 1965; Hennessy, 1966; Hirsch, 1974; Triggs, Lewison, \& Sanneman, 1974), current research in this area has primarily been driven by recent advances in technology that have provided inexpensive and effective means of vibrotactile stimulation (e.g., Benali-Khoudja, Hafez, Alexandre, \& Kheddar, 2004; Ho, Tan, \& Spence, 2005, in press; Lindeman, Yanagida, Sibert, \& Lavine, 2003; Rupert, 2000; Sorkin, 1987). Over the years, researchers have investigated the effectiveness of vibrotactile stimuli (and also proprioceptive cues) presented to the torso (e.g., Ho, Tan, \& Spence, 2005; Jones, Lockyer, \& Piateski, 2006; Lindeman, Yanagida, Sibert, \& Lavine, 2003; van Erp, 2005; van Erp \& van Veen, 2004), head (e.g., Gilliland \& Schlegel, 1994), hands (e.g., Burke, Gilson, \& Jagacinski, 1980; Schumann, Godthelp, Farber, \& Wontorra, 1993; Vitense, Jacko, \& Emery, 2003), wrists (Sklar \& Sarter, 1999), buttocks (Lee, Hoffman, \& Hayes, 2004; McGehee \& Raby, 2003), and even to the feet (Godthelp \& Schumann, 1993; Janssen \& Nilsson, 1993; Janssen \& Thomas, 1997; Kume, Shirai, Tsuda, \& Hatada, 1998).

Research over the last decade has demonstrated that tactile displays can be effectively used to convey information under conditions of high gravitational load when visual information may be severely degraded (e.g., van Veen \& van Erp, 2000; although see Bhargava et al., 2005). It has also been shown that tactile stimulators placed on the body (i.e., over clothing) can be used to successfully resolve the spatial disorientation experi- 
enced by pilots (e.g., Rupert, 2000), as well to convey aircraft position and motion information (e.g., Levison, Tanner, \& Triggs, 1973; Rupert, Guedry, \& Reschke, 1994). Tactile interfaces have even been used to support the orientation awareness of astronauts in micro-gravity environments (van Erp \& van Veen, 2000). A growing number of studies have also started to investigate the potential for using tactile displays to provide route finding information to travelers (Ho \& Spence, 2006; van Erp, van Veen, Jansen, \& Dobbins, 2005; see also Nagel, Carl, Kringe, Martin, \& Konig, 2005), to improve the perception and composition of music (Gunther \& O'Modhrain, 2003), to cue driver attention in vehicular settings (e.g., Ho, Tan, \& Spence, 2005, 2006; Lee, Hoffman, \& Hayes, 2004), to provide silent alerts to mobile phone users (Brown \& Kaaresoja, 2006; Brown, Brewster, \& Purchase, $2006 \mathrm{~b}$ ), and/or to manipulate a user's visual attention in a variety of multisensory task settings (e.g., Gray \& Tan, 2002; Hopp, Smith, Clegg, \& Heggestad, 2005; Hopp-Levine, Smith, Clegg, \& Heggestad, 2006; Tan, Gray, Young, \& Traylor, 2003).

Tactile displays have also been used to signal contact with a remote object in teleoperation and virtual environment applications (e.g., Dennerlein, Millman, \& Howe, 1997), as well as to provide crude force information from a remote robot to the human operator for dexterous telemanipulation (e.g., Murray, Klatzky, \& Khosla, 2003; see Howe \& Matsuoka, 1999, for a description of a remote palpation system capable of conveying tactile information from the inside of a patient's body to the surgeon's fingertips during minimally invasive robotic surgical procedures; see also Kajimoto, Kawakami, Tachi, \& Inami, 2004). Tactile interfaces have been used to enhance the realism, or the sense of presence, of virtual events such as tapping (e.g., Okamura, Cutkosky, \& Dennerlein, 2001), handling contacts (Lindeman, Templeman, Sibert, \& Cutler, 2002), and even driving a scooter (Deligiannidis, 2005; Deligiannidis \& Jacob, 2006) in a virtual environment (see also Hoffman, 1998; Hoffman, Hollander, Schroder, Rousseau, \& Furness, 1998; Kontarinis \& Howe, 1995; see Carlin, Hoffman, \& Weghorst, 1997, for the use of tactile stimuli in virtual reality environments to treat certain phobias). Tactile stimulation, in the form of haptic interfaces, has also been adopted in concert with stimulation from other sensory modalities in order to provide reliable feedback in a variety of different interface settings, such as, for example, in mouse-pointing tasks (e.g., Akamatsu, MacKenzie, \& Hasbroucq, 1995; see also Cockburn \& Brewster, 2005; Hoffman et al., 1998; Vitense, Jacko, \& Emery, 2003).

One advantage associated with the use of tactile displays is that they might not be affected by many of the limitations that constrain a person's ability to process information in the other sensory modalities (such as vision or audition). For example, tactile information appears to degrade less than visual information in high-G load environments (see van Veen \& van Erp, 2001 ), is not adversely affected by high levels of background noise (see Brown, Galloway, \& Gildersleeve, 1965; Wilkins \& Acton, 1982), is not dependent for its effectiveness on the current direction of fixation (as is vision), and finally, temporal discrimination performance has been shown to be superior in touch than in vision (e.g., Lechelt, 1975; Spence, Shore, \& Klein, 2001). Indeed, it has even been suggested that tactile stimuli may have an automatic ability to capture attention (see Geldard, 1960; Gilson, Ventola, \& Fenton, 1975; Von Haller Gilmer, 1960). Moreover, it has been argued that the 3D nature of the body surface might facilitate the interpretation of $3 \mathrm{D}$ spatial information that typically has to be translated from 2D when presented visually (e.g., van Veen \& van Erp, 2001; see also Jeram \& Prasad, 2005).

Despite the rapidly growing increase of interest in the use of tactile interfaces in a variety of application settings, tactile information processing has been studied in far less detail than the processing of stimuli in other sensory modalities, such as vision and audition. What's more, the majority of psychophysical studies that have attempted to investigate the nature of any fundamental limitations on tactile information processing have typically tended to restrict their stimulus presentation to small and highly sensitive regions of the skin surface, such as the fingertips (e.g., Ginsburg \& Pringle, 1988; Hillstrom, Shapiro, \& Spence, 2002; Spence, 2002), and, even more recently, the tongue (see Kupers \& 
Ptito, 2004; Sampaio, Maris, \& Bach-y-Rita, 2001). Consequently, the information processing limitations affecting stimuli presented to the rest of the body surface are, with very few exceptions (see Cholewiak \& Collins, 2000, 2003; Cholewiak, Brill, \& Schwab, 2004; Geldard \& Sherrick, 1965; Weinstein, 1968), largely unknown.

Moreover, although the hands may well have better discriminative power than the rest of the body surface (note also that a larger proportion of the somatosensory cortex is devoted to the representation of the hands than to other parts of the body given their relative size; e.g., Nakamura et al., 1998; Narici et al., 1991; Penfield \& Boldrey, 1937), the fact that the majority of human interfaces already require their operators to use the hands actively (e.g., to steer, to change gear, and/or to operate the controls in a vehicle; see Burke, Gilson, \& Jagacinski, 1980), highlights the importance of investigating the potential for using other parts of the body surface as an alternative means of information presentation (e.g., McGehee, Raby, Lee, \& Nourse, 2001; Rupert, 2000; Van Erp \& Van Veen, 2003). Given their relative underutilization as "receiving surfaces" for informational transfer, stimulation of certain body parts (such as the backside) might prove to be far more effective in alerting human operators than stimulation presented to the hands. What's more, the relatively poor spatial resolution of the back is well compensated for by the larger contiguous area for stimulation that it provides (see Tan et al., 2003).

Second, in many real-life interface environments, the stimuli that a human operator will need to process and respond to will likely occur in a variety of different sensory modalities (i.e., in the case of an aircraft pilot, visual signals from an airplane's instrumentation panel, auditory instructions from flight control, and tactile signals from any vibrotactile interface or stick shaker; see Ho \& Spence, 2006; Spence \& Driver, 1997), leading to the necessity of studying such limitations on tactile information processing across the body surface under the more realistic conditions of multisensory stimulation (at least if one's aim is to elucidate the actual limitations constraining effective tactile information processing in real-word environments).

\section{Low-Level Limitations on Tactile Information Processing}

Early studies in which researchers attempted to investigate tactile perception across the body surface have given rise to a wealth of knowledge regarding psychophysical thresholds (i.e., relative discriminability or spatial resolution as measured by two-point discrimination thresholds, as well as frequency and amplitude discrimination thresholds) for stimuli presented to different body locations (e.g., Weinstein, 1968; though see Johnson, Van Boven, \& Hsiao, 1994, for some of the problems associated with the use of the two-point discrimination threshold to assess tactile spatial resolution; and see Gibson \& Craig, 2002; Stevens \& Choo, 1996, for alternative means of measuring tactile acuity across the body surface involving participants having to try and detect spatial gaps in a stimulus presented on the skin surface).

The focus of much of this early research was on mapping the low-level and/or peripheral constraints on information processing for stimuli presented in isolation and typically in the absence of any simultaneous stimulation to another sensory modality (i.e., under conditions of unimodal stimulus presentation; e.g., Brown, Spern, Schmitt, \& Solomon, 1966; Cholewiak et al., 2004; Geldard \& Sherrick, 1965; Verrillo \& Gescheider, 1992; Weinstein, 1968). Most studies were primarily motivated by the desire to assist individuals with severe visual and/or hearing impairments through sensory substitution. Novel devices, known as "tactile vision substitution systems" (TVSS) were developed. These devices enabled a visual image scanned by a televisiontype camera to be converted into patterns presented to the skin by means of a 2D matrix of tactile stimulators (e.g., Bach-y-Rita et al., 1969). The TVSS was utilized during the early 1970s to study the ability of visually impaired individuals to interpret visual information presented to the skin (e.g., Bach-y-Rita et al., 1969; Collins, 1970; Craig, 1973; Linvill \& Bliss, 1966; White, 1970; see Bach-y-Rita, 2004, for a review; see also Back-y-Rita, Webster, Tompkins, \& Crabb, 1987; for a more recent attempt to use TVSS in different applied settings see Saunders, Hill, \& Franklin, 1981, for the 
use of tactile sensory substitution systems in deaf children).

Extensive research has shown that participants can use such TVSS devices to correctly and "intuitively" perceive simple patterns of stimulation, such as vertical, horizontal and diagonal lines. By contrast, only expert and well-trained users could identify common objects or faces (e.g., Bach-y-Rita, 1972; see also Bach-y-Rita, 1974, for the report of certain expert users being able to perform electronic assembly under a microscope using TVSS). The poor spatial resolution of the skin surface (as compared to the retina), however, prevented the TVSS from being used successfully for tasks such as the exploration of visual environments or navigation (though see Segond \& Weiss, 2005, for a recent attempt to use a TVSS device to facilitate spatial navigation). Only one of the TVSS devices survived over the years and obtained a relatively large commercial and applied success: the "Optacon" developed by Bliss, Katcher, Rogers, and Shepard (1970). This device converted printed letters scanned by a camera to vibrotactile patterns of stimulation presented to the fingertips and was reported to allow expert users to read up to 90 words per minute.

It appears clear therefore that researchers in the 1970s focused on characterizing a user's ability to use the body surface for displaying images or communicating speech, rather than on exploring the nature of any higher-level (or more cognitive) information processing limitations that may be evident under more ecologically valid conditions of parallel stimulation across the body surface presumably involving central processing and most likely multisensory stimulation.

The earlier studies exploring tactile perception showed that certain parts of the body, such as the hands and the face, had lower detection and two-point, frequency, and amplitude discrimination thresholds (see Verrillo \& Gescheider, 1992; Weinstein, 1968) than other parts of the body (such as, for example, the feet and legs). That is, when tactile stimuli are presented on these body surfaces, less pressure needs to be applied in order for people to detect the presence of stimulation. Moreover, people are able to discriminate that two (rather than one) stimuli have been presented at the same time at smaller interstimulus distances on these areas than for distances presented on other areas of the skin, and people also tend to exhibit higher sensitivity to changes in the frequency and/or amplitude of vibrotactile stimulation (although note that Summers et al., 2005, have reported better amplitude discrimination performance for tactile stimuli presented on the palmar surface of the wrist than for stimuli presented to the fingertip; see also Verrillo \& Chamberlain, 1972).

Research has shown that when different locations across the whole body surface are assessed, the larger the separation between the points of the skin stimulated, the better the participant's performance in reporting the location of stimulation (e.g., Cholewiak \& Craig, 1984; see also Cholewiak et al., 2004; for a similar result obtained under conditions where the stimuli were presented at sites around the abdomen). It is also interesting to note that performance in identifying the specific bodily location that has been stimulated is better when the stimuli are presented near some anatomical reference points or "anchors" (i.e., the wrist, elbow, shoulder of the arm, spine, and navel; Cholewiak \& Collins, 2003; Cholewiak et al., 2004). Finally, the perceived position of the stimuli presented at different body locations has been shown to be shifted toward the location of these body anchors (e.g., Cholewiak \& Collins, 2003).

\section{Central Limitations of Unimodal Information Processing}

As mentioned above, most research on tactile communication systems that has attempted to utilize the body surface has typically evaluated a user's ability to receive images on their back (e.g., think of the TVSS system introduced by Bach-y-Rita, Collins, Saunders, White \& Scadden, 1969), or text on the torso (e.g., the "vibratese" language by Geldard, 1957) or over the entire body surface (e.g., the "optohapt" system introduced by Geldard, 1966a, 1966b). There are many reasons why these earlier prototypes did not enjoy commercial success (except for the simpler versions such 
as TactaidVII), with the key reason most likely being the complexity of the coding scheme and the amount of training required before a user became proficient (see Tan \& Pentland, 2001, for a review). Not surprisingly then, the recent trend appears to be toward presenting much simpler vibrotactile patterns on the body surface using duration, intensity and location cues to convey information that has a natural mapping to the body surface (e.g., using the tactors on a belt around the torso to indicate the heading in which a boat should be directed), assuming that high-level performance can be achieved by using simple and distinct tactile stimulation patterns. As we will show later in this review, however, there are fundamental cognitive limits on a human's ability to process even highly discriminable tactile stimuli.

Over the last 50 years, a numbers of different welldocumented fundamental limitations have been reported to affect visual information processing (note that the majority of studies of central information processing in humans have been carried out in the visual modality; see Pashler, 1998), in particular with regard to the number of items that can be selected or consciously represented at any one time (see Atkinson, Campbell, \& Francis, 1976a; Jevons, 1871; Kaufman, Lord, Reese, \& Volkmann, 1949; Lechelt, 1971; Saltzman \& Garner, 1948; Trick \& Pylyshyn, 1993; see Cowan, 2001, for a review). That is, the majority of visual studies in which participants were required to enumerate the number of stimuli presented in a display at any one time have reported there to be a difference in the accuracy and latency of behavioral responses when small versus large numbers of items were presented (e.g., Atkinson, Campbell, et al. 1976a; Atkinson, Francis, \& Campbell, 1976b; Jevons, 1871; Trick \& Pylyshyn, 1993, 1994; Weiss, 1965). When the number of items presented is small (typically between one and four stimuli) they appear to be processed very rapidly and nearly errorlessly (e.g., Atkinson, Campbell, et al., 1976a,b; Atkinson, Francis, 1976). Increasing the number of items presented above four typically produces a large increase in both average response latencies and in error rates, often giving rise to a discontinuity in the slope of the latency and error functions.
Visual limitations have also been reported to affect the ability of people to correctly detect the presence of changes introduced between one visual scene and the next, both in laboratory settings, and under more ecologically valid conditions (showing people surprisingly failing to perform this task accurately; a phenomenon known as "change blindness"; e.g., DiVita, Obermayer, Nugent, \& Linville, 2004; French, 1953; Grimes, 1996; Hochberg, 1968; Rensink, 2002; Velichkovsky, Dornhoefer, Kopf, Helmert, \& Joos, 2002).

Limitations in information processing have also been studied when tactile stimuli are presented to the fingertips. For example, Lechelt (1974) reported that people's tactile temporal numerosity judgments were linearly related to the number of stimuli presented (with a slope less than 1; i.e., showing non-optimal performance), and that the slope of the function fitting the performance data was influenced by the rate of stimulus presentation (with performance decreasing rapidly as the rate of stimulus presentation increased above 12 stimuli/sec; see also Lechelt, 1975; Riggs et al., 2006). However, it is only recently that similar limitations in unimodal tactile information processing have been investigated across the body surface. In particular, Gallace, Tan, \& Spence (2006a) presented variable numbers of vibrotactile stimuli in parallel over the body surface while the participants in their study had to report the number of stimuli that they perceived. The results of these experiments showed that the accuracy of a participant's numerosity judgments when counting up to 7 vibrotactile stimuli distributed across the body surface decreased linearly as the number of items presented in the display increased (see Figure 1).

The dramatic and somewhat surprising result to emerge from Gallace et al.'s (2006a) research is that error rates became very high $(>50 \%)$ whenever more than 2 tactile stimuli were presented (see also Alluisi, Morgan, \& Hawkes, 1965; Geldard \& Sherrick, 1965; Posey \& James, 1976; cf. Lakatos \& Shepard, 1997). However, it is important to note that we still do not know how these limits might change when the tactile stimuli presented across the body group to form recognizable patterns (e.g., triangles, squares, 
A)

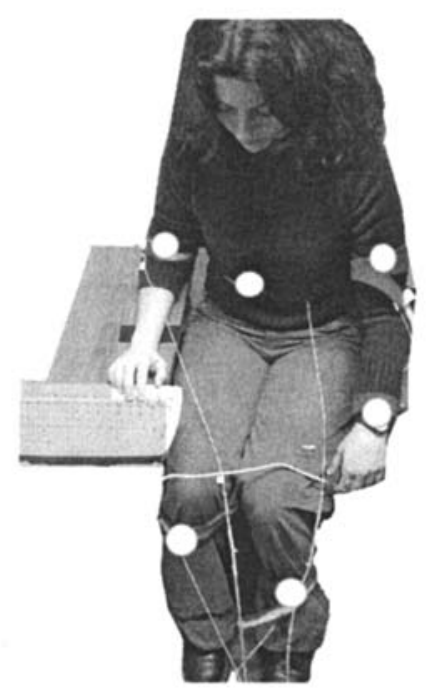

B)

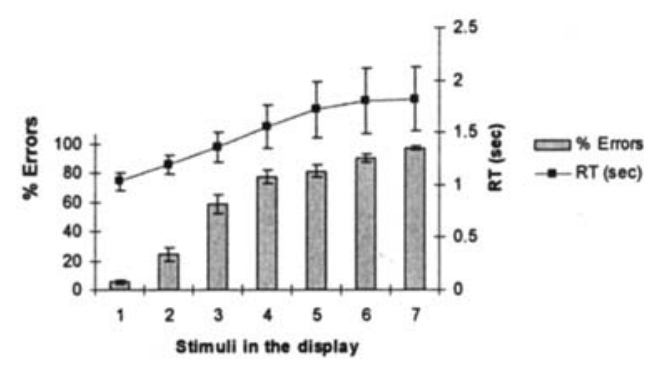

Figure I. Experimental setup and results from Gallace et al.'s (2006a) tactile numerosity judgment experiments. A) Positions on the body where the tactors were placed (note that one tactor was placed on the left side of participant's lower back, and is not represented in this picture). B) Mean error rates and RTs (on different axes) as a function of the number of tactile stimuli presented. Error bars represent the standard errors of the means.

diamonds, etc; cf. Schotz, 1958). Indeed, on the basis of the visual literature it should be expected that better performance would be observed when the stimuli are organized perceptually to form simple patterns (e.g., Atkinson, Francis, et al., 1976b).

There are many ways of displaying coherent patterns across the body surface. At one extreme, dense arrays are used over a relatively small stimulation area covering the distal pad of a finger or the palm of a hand (Iwata, Yano, \& Kawamura, 2002; Linvill \& Bliss, 1966; Pawluk, Buskirk, Killebrew, Hsiao, \& Johnson, 1998; Summers \& Chanter, 2002). At the other extreme, sparsely spaced tactors are used over a relatively large area covering the trunk and sometimes the arms and legs as well (Bach-y-Rita et al., 1969; Geldard, 1966b; Rupert, 2000). In an earlier attempt to investigate this topic, Sherrick (1995) presented vibrotactile stimuli to ten possible locations across the body surface. Their results showed that increasing the number of stimuli and the degree of overlap between the patterns to be compared by the participants resulted in an increasing number of errors in detecting the similarity or difference between consecutively presented patterns (see also Geldard, 1968). Current research in our laboratory is now underway in order to investigate more extensively the perception of tactile patterns over the whole body surface.

It should be noted that the limitations encountered in Gallace et al.'s (2006a, 2007a) tactile information processing studies appear to be much more severe than those reported previously on the basis of studies when stimuli have been presented to the hands/fingers instead (though see Geldard, 1968, for the report of better performance obtained in a pattern recognition task under conditions in which the stimuli were presented to the body as compared to conditions in which the stimuli were presented to the fingers). As such, these results immediately provide an important constraint on the amount of information that can be presented at any one time using tactile stimulation over the body surface. In particular, they suggest that tactile stimulation might be most effective in alerting an interface operator, or in conveying directional information (see von Haller Gilmer, 1960; Hennessy, 1966; Ho, Tan, \& Spence, 2005 ), rather than in presenting multiple stimuli at the same time.

However, it is important to note that when presenting tactile stimuli in any experimental setup, it is likely that there will always be a number of uncontrolled sources of tactile stimulation on the participant's body at the same time, but which cannot be fully controlled 
by the experimenter (i.e., such as the feeling of the participants' clothing on their bodies, the feeling of their contact with the chair on which they are sitting, the pressure of the fingers/foot on response buttons, etc.; although see Graziano, Alisharan, $\mathrm{Hu}$, \& Gross, 2002). These uncontrolled variables might in part explain certain differences between the results in information processing reported between tactile and visual perception (nevertheless, we would also expect these uncontrolled tactile stimuli to be present in any other interface setting as well).

Recent research has also provided the first evidence of a tactile analog of the phenomenon of change blindness (see Gallace, Tan, Spence, 2005, 2006b, 2007a), with participants failing to detect a significant proportion (up to $30 \%$ ) of positional changes between two consecutively presented tactile patterns even when separated by intervals as short as $110 \mathrm{~ms}$ and when a distractor was presented between the two to-be-compared tactile patters (see Figure 2).

Interestingly, in Gallace et al.'s (2005, 2006b, 2007a) studies, the failure to detect changes to tactile stimuli presented over the body surface was observed when no more than two to three tactors were activated. These results contrast with the findings reported in previous studies of visual change blindness, where failures to detect change are typically only reported for complex and detailed visual scenes containing at least five items (e.g., Rensink, 2000). It may be the case that change blindness in touch as well as in vision might be related to the failure of a stimulus to reach awareness and/or draw spatial attention to itself within a multisensory/amodal spatial representation where the change took place (Gallace et al., 2006b). This might be determined by the competition between concurrently stimulated positions (see Cole, Kentridge, Gellatly, \& Heywood, 2003; Desimone \& Duncan, 1995), and/or the limited information processing resources available to humans (see Wright, Green, \& Baker, 2000). Neuroscientific support for this view comes from the results of a study reported by Downar, Crawley, Mikulis, and Davis (2000). Using event-related fMRI, Downar

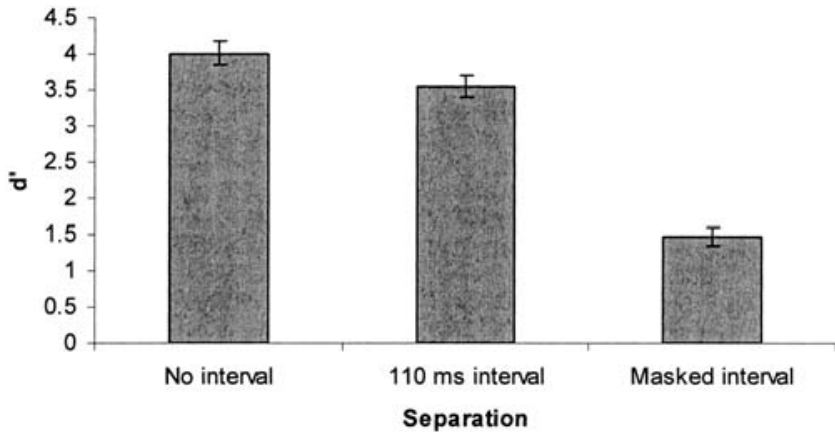

Figure 2. Performance in Gallace et al.'s (2006b) tactile change detection experiment as a function of the experimental condition. In the No interval condition, the two to-be-compared tactile patterns were presented sequentially, without any gap between them. In the 100 ms interval condition, the two patterns were separated by a 110 ms empty interstimulus interval. In the Masked interval condition, the two patterns were separated by an interval consisting of a $50 \mathrm{~ms}$ empty interval, followed by a 10 ms vibrotactile mask consisting of all 7 tactors being activated simultaneously, and then finally a second 50 ms empty interval. The mean d' values represent the participants' sensitivity (i.e., the higher the value, the easier the participants found it to detect the presence of changes). Error bars represent the standard errors of the means.

and his colleagues highlighted the activation of a right-hemisphere network including the temporoparietal junction (TPJ) whenever participants had to detect visual, auditory, or tactile changes (see also Beck, Rees, Frith, \& Lavie, 2001). Interestingly, the right TPJ is an area that is consistently reported to be involved in the subjective awareness of spatial information (e.g., Karnath, Ferber, \& Himmelbach, 2001; Vallar, 2001).

The results of the recent behavioral studies reviewed here (e.g., Gallace et al., 2006b, 2007a, 2007b) highlight important limitations in tactile information processing when stimuli are presented over the body surface (see also Gallace \& Spence, 2007). In particular, these limitations seem to be more severe than those identified previously for visual information processing, and also more severe than those identified previously when tactile stimuli were presented to the hands. What appears clear then is that one cannot simply infer the limits constraining a person's ability to process tactile 
stimuli presented across the body surface on the basis of our current knowledge regarding tactile information processing on the hands or on the basis of limitations regarding visual information processing under apparently similar stimulation conditions.

\section{$5 \quad$ Processing of Tactile Information Under Conditions of Multisensory Stimulation}

The last few years have seen a gradual shift from the propensity to study information processing within individual sensory modalities toward the investigation of processes more related to the integration of information from different sensory modalities (e.g., Calvert, Spence, \& Stein, 2004; Spence \& Driver, 2004). Researchers have argued that inputs from different sensory modalities may interact at many different stages of neural information processing, and that certain cognitive systems, such as the one thought to control the allocation of spatial attention, may be multisensorially constrained (e.g., Spence \& Driver, 2004). Therefore, it might be possible that limitations in the resources available for information processing are not modality-specific but are instead centrally determined and shared between different sensory modalities (e.g., Gallace, Auvray, et al., 2006; Gallace et al., 2006a; cf. Lavie, 2005).

As noted earlier, the majority of previous studies of tactile information processing for stimuli presented across the body surface, including some of our own recent research in this area, have focused on conditions of unimodal tactile stimulation. While this obviously represents a sensible approach if one is trying to understand the fundamental limitations on tactile information processing, it is important to note that one also needs to study tactile information processing under conditions of multisensory stimulation. Indeed, the study of tactile processing when stimuli are simultaneously presented to other sensory modalities might enable one to derive constraints for the design of ef- fective tactile interfaces for real-world environments and/or interactions that are ultimately more useful. ${ }^{1}$

It is important to note here that in many real-world human-machine interface environments, the information available to an interface operator is often, if not always, multisensory in nature. That is, the main task for human-operators will not be just to monitor the information received via a tactile interface, but rather to use this information during a specific and alternative resource-consuming primary task (most likely involving highly cognitively demanding visual and/or auditory information processing; e.g., see Senders, Kristofferson, Levison, Dietrich, \& Ward, 1967; Sivak, 1996). Therefore, it becomes extremely important for research on the effectiveness of tactile interfaces to study their use under conditions of multisensory stimulus presentation. To date, virtually no research has attempted to investigate how the limits on tactile information processing change under conditions of multisensory stimulation.

At least two different and mutually exclusive predictions can be made in terms of the results that would be expected under such conditions of multisensory stimulus presentation: 1) Processing limitations on tactile information under conditions of dual task bimodal stimulation (where visual information must also be processed) are the same as (and predictable on the basis of) the performance reported in the unimodal stimulus displays. This would be expected if the neural systems processing visual and tactile stimuli are entirely independent (i.e., if they access separate unimodal resources, one for each sensory modality; see Martin, 1980; Wickens, 1980; cf. Duncan, Martens, \& Ward, 1997; Hennessy, 1966; Lavie, 2005; Soto-Faraco \& Spence, 2002); 2) The processing of tactile information is dramatically impaired under conditions of dual-task bimodal stimulation rela-

1. One exception with regard to previous research in this area comes from the study of tactile aids to lipreading. There is evidence that the transmission of speech features (such as voicing) decreases under the tactual-visual bimodal condition as compared to the unimodal tactual condition due to low-level crossmodal perceptual interference (e.g., Yuan, Reed, \& Durlach, 2003, 2005), and that the ability to integrate cues across the two sensory modalities at both segmental and connected speech levels are limited, presumably due to insufficient training of high-level integration strategies (Kirman, 1973; Yuan et al., 2005). 
tive to conditions of unimodal stimulus presentation. This prediction follows on from the idea that dividing attention between two or more sensory modalities can lead to impaired performance when compared to performance under conditions where attention is focused on a single sensory modality instead (e.g., Spence \& Driver, 1997; Spence, Nicholls, \& Driver, 2001; Spence, Shore, \& Klein, 2001), and/or the same cognitive limitations affect processing of different stimuli, no matter their modality of origin. Moreover, a decrease in performance under conditions of multisensory stimulus presentation might be expected whenever tasks presented in different sensory modalities share the same processing resources.

The first empirical attempts to answer these important questions have recently been conducted by Gallace et al. (2007b). Specifically, we investigated numerosity judgments using both unimodal and bimodal displays consisting of $1-6$ vibrotactile stimuli (presented over the body surface) and $1-6$ visual stimuli (seen on the body via mirror reflection). Participants in our study were required to count the number of stimuli regardless of the modality of presentation. Importantly, the accuracy of participants' bimodal numerosity judgments was not predicted by their performance on the unimodal displays. In fact, unspeeded bimodal numerosity judgments were significantly worse than would have been predicted on the basis of their performance on the unimodal numerosity judgment task (see Figure 3). This result clearly suggests that cognitive resources and/or common processing systems may be shared between different sensory modalities (and for different tasks, such as change detection or numerosity judgments).

Other recent studies investigated whether the phenomenon of tactile change blindness (Gallace et al., 2005,2006 b , 2007a) might also be elicited crossmodally by the presentation of a visual mask (Gallace, Auvray, et al., 2006; see also Auvray, Gallace, Tan, \& Spence, in press). In particular, the participants in Gallace, Auvray, et al.'s (2006) study were required to make same versus different judgments regarding two successively presented displays composed of $2-3$ vibrotactile stimuli presented across the body surface. Their results confirmed previous observation regarding the presence of the phenomenon of change blindness in tactile perception (Gallace et al., 2005, 2006c, 2007a). That is, change detection performance was found to be near-perfect when the two displays were presented one directly after the other, but participants failed to detect many of the changes between the two tactile displays when they were separated by an empty interval (cf. Gallace et al., 2005, 2006b).

However, the most interesting and critical data to emerge from this experiment was that tactile change detection performance deteriorated still further when the presentation of a local (i.e., a mudsplash) or global visual transient coincided with the onset of the second tactile pattern. Finally, it is important to note that this pattern of results was also obtained in a second experiment in which the visual stimuli were placed on the wall $2 \mathrm{~m}$ in front of the participant's head (rather then being placed on the participant's body and seen via mirror reflection; cf. Thomas, Press, \& Haggard, 2006). Therefore, once again, it appeared difficult to predict people's performance in a tactile discrimination task (one in which the stimuli were presented across the body surface) under conditions where visual stimuli were also presented (see Figure 4).

Note that recent results obtained by Auvray et al. (2007) using visual displays (i.e., asking participants to detect the presence of visual changes between two consecutively presented patterns of stimulation) showed that visual change blindness cannot be elicited by the presentation of vibrotactile distractors at the same time as the change in the visual scene (at least for simple visual displays consisting of patterns of no more than two or three stimuli). The latter result can therefore be taken to suggest that stimuli presented via a tactile interface might not impair the processing of visual information (i.e., on a visual display).

The results of these recent studies of multisensory processing across the body surface might also be taken to suggest that using different sensory modalities in a redundant manner (i.e., when different modalities carry the same content of information) should improve the performance of human interface operators (cf. Spence, Shore, \& Klein, 2001; Spence \& Driver, 1997). With reference to this point, it has recently been shown that when using a vibrotactile display mounted in a driver's 
A)

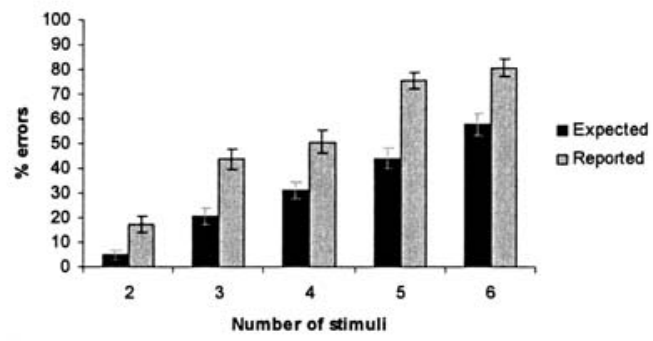

B)

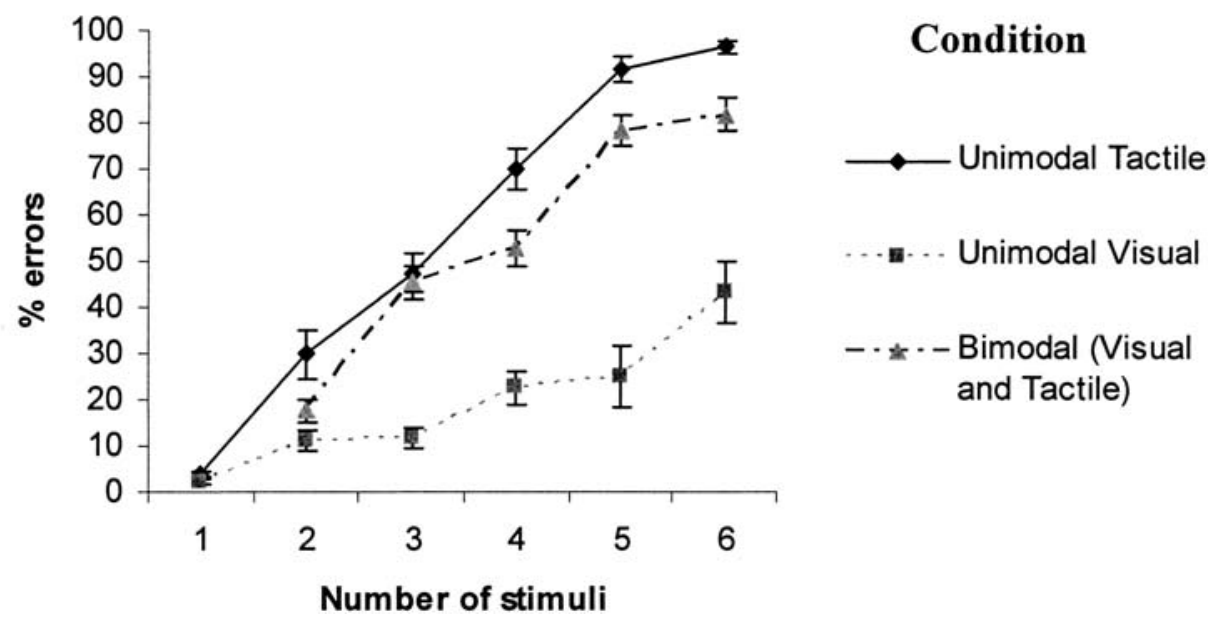

Figure 3. The results from Gallace et al.'s (2007b) recent visuo-tactile numerosity judgment study. A) Mean expected (as a function of the performance in unimodal numerosity judgment's tasks) and reported percentage of errors as a function of the number of bimodal (visuo-tactile) stimuli presented in the display. Note that the visual stimuli consisted of the illumination of LEDs placed on the same positions on the body as the vibrotactile stimulators, and seen by participants via mirror reflection. B) Mean error rates as a function of the number of stimuli presented in the display for all experimental conditions used. In the unimodal visual condition, only visual stimuli were presented. In the unimodal tactile condition, only tactile stimuli were presented. In the bimodal condition, visual and tactile stimuli were presented from different positions (overlapping or not overlapping) on the participant's body. Error bars represent the standard errors of the means.

seat, the performance of participants in a driving simulator setting was better when redundant multisensory (i.e., visuo-tactile) information was presented as compared to a condition involving unimodal stimulus presentation (van Erp \& van Veen, 2004). By contrast, it now appears clear that when the information carried by two (or more) sensory modalities is non-redundant (as in the recent studies performed in our laboratory), severe information processing limitations may arise. This important topic should therefore be further addressed in 
future research regarding tactile and, more generally, multisensory processing across the body surface.

\section{The Role of Practice on Tactile Information Processing}

Early studies on tactile information processing suggested that people can be trained to perceive more than 30 words per minute using the tactile alphabet "vibratese" (see Geldard, 1960, for an early review of research in this area; see also von Haller Gilmer, 1961). The large individual differences that have been reported in previous studies might also be consistent with the importance of practice in modulating tactile discrimina-

A)

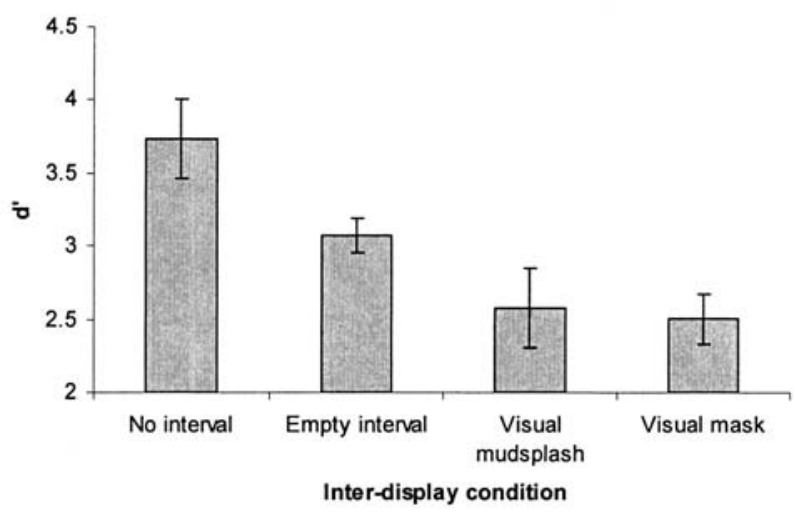

B)

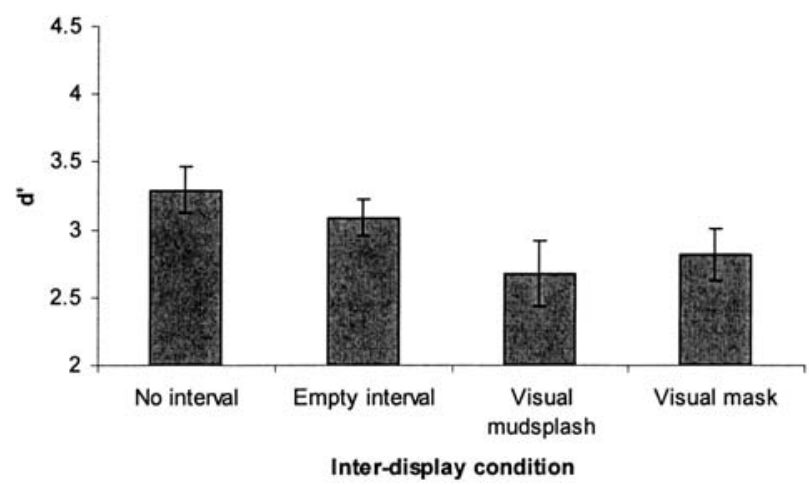

tion performance (see Craig, 1977; for the report of two sighted individuals who, once trained to use tactile displays, achieved a discrimination ability superior even to that of blind individuals who were highly experienced with such displays; cf. Craig, 1977; Kóbor, Füredi, Kovács, Spence, \& Vidnyánszky, 2006). It is therefore conceivable that any difference between the information processing capacities of the "hands" versus the rest of the body might, at least in part, be related to the fact that certain body parts are generally underused as receptor surfaces for information transfer (note however that the lower density of tactile receptors as one moves away from the fingers might play an important role in constraining tactile processing across the body surface). In other words, people may simply not be used to attending to large parts of their body surface (Godde,

Figure 4. $A-B)$ Performance in two tactile change detection experiments (modified from Gallace, Auvray, et al. 2006, Gallace et al. 2006b). Note that the participants in these studies were required to detect the presence of a positional change taking place between two consecutively presented tactile displays, consisting of 2-3 tactors being activated across their body, when visual distractors were also presented. A) The mean d'values obtained when the stimuli were seen via mirror reflection (Experiment I) for each experimental condition. In the No interval condition, no interval between the two consecutively-presented tactile displays was presented. In the Empty interval condition, a $50 \mathrm{~ms}$ interval was presented between the two tactile displays. In the Visual mudsplash condition, a visual transient was presented for $100 \mathrm{~ms}$ at the same time as the onset of the second vibrotactile pattern (although from a position that was noncoincident with the position of the change). In the Visual mask condition, a visual mask composed of the illumination of all 6 visual stimuli (LEDS) was presented at the same time as the onset of the second vibrotactile pattern. Mean d' values represent the sensitivity of participants (i.e., the higher the value the easier participants found it to detect the presence of a change). B) The mean d' values obtained when the visual stimuli were seen mounted on a wall $2 \mathrm{~m}$ away from the participants (Experiment 2; i.e., when the visual stimuli were matched in position and layout to the mirror condition, but where the lights now occupied different spatial location to the participant's body where the changes were occurring) for each experimental condition. The same conditions were adopted as in Experiment I. Error bars represent the standard errors of the means. 
Ehrhardt, \& Braun, 2003; see also Mahar, Mackenzie, \& McNicol, 1994).

Using neuroimaging techniques in humans, it has been shown that repeated stimulation of a specific body part can lead to an improvement of tactile discrimination performance for that part of the body and to a concomitant increase of activation across primary (SI) and secondary (SII) somatosensory cortical areas representing the stimulated body part (as measured using fMRI; Hodzic, Veit, Karim, Erb, \& Godde, 2004; see also Elbert, Pantev, Wienbruch, Rockstroh, \& Taub, 1995; Godde, Stauffenberg, Spengler, \& Dinse, 2000; see also Recanzone, Jenkins, Hradek, \& Merzenich, 1992, for similar results obtained in neurophysiological studies of the monkey brain). Such results highlight the plasticity of the cerebral network processing sensory stimuli (including those presented on the body).

It is conceivable therefore that training participants to use their body surfaces as a means of perceiving information, and paying attention to information that is presented to certain parts of it (that they might not otherwise be used to attending to), might reduce, at least in part, any difference reported between processing in highly sensitive body areas like the hands and the rest of the body surface (e.g., E. J. Gibson, 1963; see Elbert et al., 1995). It should also be noted that certain limitations on information processing across the body might be hard-wired, whereas others might be susceptible to improvement given the appropriate practice/experience. This clearly represents another important area for future research.

\section{Conclusions}

The findings highlighted in this review show that it is only very recently that researchers have started to consider more extensively the fundamental role of $\mathrm{cog}$ nitive (i.e., higher level), as well as the previously studied, peripheral, limitations on tactile information processing across the body surface. Recent studies have shown that people are limited in counting the number of stimuli presented at any one time on their body (at least when these stimuli are not configured to create/ represent a recognizable tactile pattern). Similarly, simple changes between two consecutively presented tactile patterns can often go unnoticed if the change does not give rise to a transient (i.e., when a gap is presented between the two patterns). Interestingly, the presentation of irrelevant visual information, together with tactile information that participants have to analyze, can lead to a disruption of tactile information processing.

These recent results highlight the important role played by central limitations in limiting tactile processing for stimuli presented across the body surface. Note that the suggestion regarding the importance of central, as compared to peripheral, limitations was only previously made on the basis of a limited number of studies on lip-reading by auditorily impaired individuals using tactile stimulation. Indeed, in this earlier research, it was shown that the poor performance obtained when using bimodal conditions of stimulus presentation (i.e., tactile and visual) was likely related to the poor strategies used by participants (thus showing a high-level constraint limiting tactile information processing; e.g., Bernstein, Auer, \& Tucker, 2001).

Other limitations that have not as yet been extensively studied might also be shown to affect the tactile information processing of stimuli presented across the body surface. In particular, we still do not know the limitations of temporal processing for stimuli presented on the body rather than on the hands (e.g., Lechelt, 1975). Temporal tactile information processing might also be affected by the phenomenon of "attentional blindness" (e.g., Hillstrom et al., 2002). Indeed, in visual as well as in tactile perception on the fingertips, it has been demonstrated that participants often fail to report the second of two targets in a sequence of events when both must be reported, and the second appears shortly after the first. Given that interface operators might be required to expect a particularly important signal during an ongoing stream of continuously time-varying information, it will be extremely important to determine whether the events following soon after such a signal can be correctly detected or not, and what the conditions are, if any, that lead to improved target detection (i.e., by varying the time between successive events 
and/or their position across the body; cf. Soto-Faraco \& Spence, 2002).

These limitations have now started to be more extensively addressed, but a large research effort is still needed in order to understand the many different aspects of tactile processing across the body surface. Studying the central limitations affecting tactile information processing across the body under conditions of both unimodal and multisensory stimulation may assume an even greater importance in the years to come, given the sensory decline that is predicted to affect the growing aging population (e.g., Hein \& Schubert, 2004; Sekuler \& Blake, 1987; Stevens \& Choo, 1996; Talland, 1964). Tactile interfaces might increasingly provide an additional means of stimulation for elderly individuals experiencing a reduction in sensory sensitivity in different sensory modalities (though note also that tactile sensitivity deteriorates, to some degree, over the lifespan, perhaps requiring itself additional source of stimulation; see Cauna, 1965; Schimirgk \& Rüttinger, 1980; see Harry, Niemi, Priplata, \& Collins, 2005; Moss \& Milton, 2003; Priplata, Niemi, Harry, Lipsitz, \& Collins, 2003; for recent examples of tactile stimulation being used for improving stability in the posture of elderly people).

In this literature review, we have suggested the importance of studying tactile information processing under condition of multisensory, in addition to unisensory, stimulation. Tactile interfaces are far more likely to be used under conditions where many sources of information are provided to human operators at the same time. Finally, the importance of practice in overcoming any limitations in our ability to perceive information distributed over the body surface should always be taken into account when exploring the processing capability of human interface interactions. The results of research on these topics will provide important information for the development of effective tactile interfaces for human operators in the years to come.

\section{Acknowledgments}

A. G. was supported by a grant from the Università di Milano Bicocca, Italy. H. Z. T. and C. S. were supported by a Net- work Grant from the Oxford McDonnell-Pew Centre for Cognitive Neuroscience. Correspondence regarding this article should be addressed to Alberto Gallace, Room B121, Department of Experimental Psychology, University of Oxford, Oxford, UK, OXI 3UD. E-mail: alberto.gallace@psy.ox.ac.uk.

\section{References}

Akamatsu, M., MacKenzie, I. S., \& Hasbroucq, T. (1995). A comparison of tactile, auditory, and visual feedback in a pointing task using a mouse-type device. Ergonomics, 38, $816-827$.

Alluisi, E. A., Morgan, B. B., Jr., \& Hawkes, G. R. (1965). Masking of cutaneous sensations in multiple stimulus presentations. Perceptual and Motor Skills, 20, 39-45.

Atkinson, J., Campbell, F. W., \& Francis, M. R. (1976a). The magic number $4 \pm 0$ : A new look at visual numerosity judgements. Perception, 5, 327-334.

Atkinson, J., Francis, M. R., \& Campbell, F. W. (1976b). The dependence of the visual numerosity limit on orientation, colour, and grouping in the stimulus. Perception, 5, 335342.

Auvray, M., Gallace, A., Tan, H. Z., \& Spence, C. (2007). Crossmodal change blindness between vision and touch. Acta Psychologica, 126, 79-97.

Bach-y-Rita, P. (1972). Brain mechanisms in sensory substitution. New York: Academic.

Bach-y-Rita, P. (1974). Visual information through the skin-A tactile vision substitution system. Transactions of the American Academy of Opthalmology and Otolaringology, 78, OP729-OP739.

Bach-y-Rita, P. (2004). Tactile sensory substitution studies. Annals of the New York Academy of Sciences, 1013, 83-91.

Bach-y-Rita, P., Collins, C. C., Saunders, F. A., White, B., \& Scadden, L. (1969). Vision substitution by tactile image projection. Nature, 221, 963-964.

Bach-y-Rita, P., Webster, J. G., Tompkins, W. J., \& Crabb, T. (1987). Sensory substitution for space gloves and for space robots. In Proceedings of the Workshop on Space and Telerobotic, 2, 51-57.

Beck, D. M., Rees, G., Frith, C. D., \& Lavie, N. (2001). Neural correlates of change detection and change blindness. Nature Neuroscience, 4, 645-650.

Benali-Khoudja, M., Hafez, M., Alexandre, J. M., \& Kheddar, A. (2004). Tactile interfaces: A state-of-the-art survey. International Symposium on Robotics. 
Bernstein, L. E., Auer, E. T., Jr., \& Tucker, P. E. (2001). Enhanced speechreading in deaf adults: Can short-term training/practice close the gap for hearing adults? Journal of Speech, Language, and Hearing Research, 44, 5-18.

Bhargava, A., Scott, M., Traylor, R., Chung, R., Mrozek, K., Wolter, J., et al. (2005). Effect of cognitive load on tactor location identification in zero-g. Proceedings of the 2005 World Haptics Conference (WHC05), 56-62.

Bliss, J. C., Katcher, M. H., Rogers, C. H., \& Shepard, R. P. (1970). Optical-to-tactile image conversion for the blind. IEEE Transactions on Man Machine Systems, MMS-11, 58 65.

Brown, L. M., Brewster, S. A., \& Purchase, H. C. (2006a). Multidimensional tactons for non-visual information presentation in mobile devices. Proceedings of the Eighth Conference on Human-Computer Interaction with Mobile Devices and Services, 231-238.

Brown, L. M., Brewster, S. A., \& Purchase, H. C. (2006b). Tactile crescendos and sforzandos: Applying musical techniques to tactile icon design. CHI 2006.

Brown, R. L., Galloway, W. D., \& Gildersleeve, K. R. (1965). Effects of intense noise on processing of cutaneous information of varying complexity. Perceptual \& Motor Skills, 20, 749-754.

Brown, L. M., \& Kaaresoja, T. (2006). Feel who's talking: Using tactons for mobile phone alerts. CHI 2006.

Brown, R. L., Spern, R. A., Schmitt, K., \& Solomon, A. (1966). Stimulus parameter considerations and individual differences in cutaneous sensitivity to electropulse stimulation. Perceptual \& Motor Skills, 23, 1215-1222.

Burke, M. W., Gilson, R. D., \& Jagacinski, R. J. (1980). Multi-modal information processing for visual workload relief. Ergonomics, 23, 961-975.

Burnett, G. E., \& Porter, J. M. (2001). Ubiquitous computing within cars: Designing controls for non-visual use. International Journal of Human-Computer Studies, 55, 521531.

Calvert, G., Spence, C., \& Stein, B. E. (Eds.) (2004). The handbook of multisensory processing. Cambridge, MA: MIT Press.

Carlin, A. S., Hoffman, H. G., \& Weghorst, S. (1997). Virtual reality and tactile augmentation in the treatment of spider phobia: A case report. Behaviour Research and Therapy, 35, 153-158.

Castle, H., \& Dobbins, T. D. (2004). Tactile displays for enhanced performance and safety. Defense, Security, and Cockpit Displays. Proceedings of the SPIE, 5443, 269-276.
Cauna, N. (1965). The effects of aging on the receptor organs of the human dermis. In W. Montagna (Ed.), Advances in biology of skin-Aging (vol. 6, pp. 63-96). New York: Appleton.

Cholewiak, R. W., Brill, J. C., \& Schwab, A. (2004). Vibrotactile localization on the abdomen: Effects of place and space. Perception \& Psychophysics, 66, 970-987.

Cholewiak, R. W., \& Collins, A. A. (2000). The generation of vibrotactile patterns on a linear array: Influences of body site, time, and presentation mode. Perception \& Psychophysics, 62, 1220-1235.

Cholewiak, R. W., \& Collins, A. A. (2003). Vibrotactile localization on the arm: Effects of place, space, and age. Perception \& Psychophysics, 65, 1058-1077.

Cholewiak, R. W., \& Craig, J. C. (1984). Vibrotactile pattern recognition and discrimination at several body sites. Perception \& Psychophysics, 35, 503-514.

Cockburn, A., \& Brewster, S. (2005). Multimodal feedback for the acquisition of small targets. Ergonomics, 48, 11291150 .

Cole, G. G., Kentridge, R. W., Gellatly, A. R. H., \& Heywood, C. A. (2003). Detectability of onsets versus offsets in the change detection paradigm. Journal of Vision, 3, 22-31.

Collins, C. C. (1970). Tactile television-Mechanical and electrical image projection. IEEE Transactions on Man Machine Systems, MMS-11, 69-75.

Cowan, N. (2001). The magical number 4 in short-term memory: A reconsideration of mental storage capacity. Behavioral and Brain Sciences, 24, 87-114.

Craig, J. C. (1973). Pictorial and abstract cutaneous displays. In F. A. Geldard (Ed.), Conference on cutaneous communication systems and devices, 78-83.

Craig, J. C. (1977). Vibrotactile pattern perception: Extraordinary observers. Science, 196, 450-452.

Craig, J. C., \& Sherrick, C. E. (1982). Dynamic tactile displays. In W. Schiff \& E. Foulke (Eds.), Tactile perception: A sourcebook (pp. 209-233). New York: Cambridge University Press.

Deatherage, B. H. (1972). Auditory and other sensory forms of information presentation. In H. P. Van Cott \& G. Kinkade (Eds.), Human engineering guide to equipment design (pp. 123-160). New York: John Wiley \& Sons.

Deligiannidis, L. (2005). A scooter-like device for navigation in virtual environments. Proceedings of the 2005 International Conference on Imaging Science. Systems, and Technology: Computer Graphics (CISST’05), 142-147.

Deligiannidis, L., \& Jacob, R. J. K. (2006). The VR scooter: 
Wind and tactile feedback improve user performance. IEEE VR 2006 Symposium on 3D User Interfaces.

Dennerlein, J. T., Millman, P. A., \& Howe, R. D. (1997). Vibrotactile feedback for industrial telemanipulators. Proceedings of the Sixth International Symposium on Haptic Interfaces for Virtual Environment and Teleoperator Systems, 61, 189-195.

Desimone, R., \& Duncan, J. (1995). Neural mechanisms of selective visual attention. Annual Review of Neuroscience, 18, 193-222.

DiVita, J., Obermayer, R., Nugent, W., \& Linville, J. M. (2004). Verification of the change blindness phenomenon while managing critical events on a combat information display. Human Factors, 46, 205-218.

Downar, J., Crawley, A. P., Mikulis, D. J., \& Davis, K. D. (2000). A multimodal cortical network for the detection of changes in the sensory environment. Nature Neuroscience, 3, 277-283.

Duncan, J., Martens, S., \& Ward, R. (1997). Restricted attentional capacity within but not between sensory modalities. Nature, 387, 808-810.

Elbert, T., Pantev, C., Weinbruch, C., Rockstroh, B., \& Taub, E. (1995). Increased cortical representation of the fingers of the left hand of string players. Science, 270, 305-307.

French, R. S. (1953). The discrimination of dot patterns as a function of number and average separation of dots. Journal of Experimental Psychology, 46, 1-9.

Gallace, A., Auvray, M., Tan, H. Z., \& Spence, C. (2006). Visual transients impair the detection of tactile changes: A novel case of crossmodal change blindness? Neuroscience Letters, 398, 280-285.

Gallace, A., \& Spence, C. (2007). The cognitive and neural correlates of "tactile consciousness": A multisensory perspective. Consciousness and Cognition. Available at http:// doi:10.1016/j.concog.2007.01.005.

Gallace, A., Tan, H. Z., \& Spence, C. (2005). Tactile change detection. In IEEE-Proceedings of the First World Haptic Conference (WHC 2005), 12-16.

Gallace, A., Tan, H. Z., \& Spence, C. (2006a). Numerosity judgments in tactile perception. Perception, 35, 247-266.

Gallace, A., Tan, H. Z., \& Spence, C. (2006b). Failure to detect tactile change: A tactile equivalent to the change blindness phenomenon. Psychonomic Bulletin \& Review, 13, $300-303$.

Gallace, A., Tan, H. Z., \& Spence, C. (2007a). Do “mudsplashes" induce tactile change blindness? Perception \& Psychophysics, 69, 477-486.
Gallace, A., Tan, H. Z., \& Spence, C. (2007b). Multisensory numerosity judgments. Perception \& Psychophysics, 69, 487501.

Geldard, F. A. (1957). Adventures in tactile literacy. The American Psychologist, 12, 115-124.

Geldard, F. A. (1960). Some neglected possibilities of communication. Science, 131, 1583-1588.

Geldard, F. A. (1966a). Cutaneous coding of optical signals: The optohapt. Perception of Psychophysics, 1, 377-381.

Geldard, F. A. (1966b). Body English. Random House Dictionary of the English Language (pp. 43-48). New York: Random House.

Geldard, F. A. (1968). Pattern perception by the skin. In D. R. Kenshalo (Ed.), The skin senses (pp. 304-321). Springfield, IL: Thomas.

Geldard, F. A., \& Sherrick, C. E., Jr. (1965). Multiple cutaneous stimulation: The discrimination of vibratory patterns. Journal of the Acoustical Society of America, 37, 797-801.

Gibson, E. J. (1963). Perceptual learning. Annual Review of Psychology, 14, 29-56.

Gibson, G. O., \& Craig, J. C. (2002). Gap-detection as a measure of tactile spatial sensitivity. Abstracts of the Psychonomic Society, 7, 51 .

Gibson, R. H. (1963). Electrical stimulation of pain and touch systems. Nature, 199, 307-308.

Gilliland, K., \& Schlegel, R. E. (1994). Tactile stimulation of the human head for information display. Human Factors, 36, 700-717.

Gilson, R. D., Ventola, R. W., \& Fenton, R. E. (1975). A kinesthetic-tactual display for stall deterrence. Proceedings of the Eleventh Annual Conference on Manual Control, 440-451.

Ginsburg, N., \& Pringle, L. (1988). Haptic numerosity perception: Effect of item arrangement. American Journal of Psychology, 101, 131-133.

Godde, B., Ehrhardt, J., \& Braun, C. (2003). Behavioral significance of input-dependent plasticity of human somatosensory cortex. Neuroreport, 14, 543-546.

Godde, B., Stauffenberg, B., Spengler, F., \& Dinse, H. R. (2000). Tactile coactivation-induced changes in spatial discrimination performance. Journal of Neuroscience, 20, 1597-1604.

Godthelp, H., \& Schumann, J. (1993). Intelligent accelerator: An element of driver support. In A. M. Parkes \& S. Franzen (Eds.), Driving future vehicles (pp. 265-274). London: Taylor \& Francis.

Gray, R., \& Tan, H. Z. (2002). Dynamic and predictive links 
between touch and vision. Experimental Brain Research, $145,50-55$.

Graziano, M. S. A., Alisharan, S. E., Hu, X., \& Gross, C. G. (2002). The clothing effect: Tactile neurons in the precentral gyrus do not respond to the touch of the familiar primate chair. Proceedings of the National Academy of Sciences, 99, 11930-11933.

Grimes, J. (1996). On the failure to detect changes in scenes across saccades. In. K. Atkins (Ed.), Perception: Vancouver studies in cognitive science, 5, 89-109.

Gunther, E., \& O’Modhrain, S. (2003). Cutaneous grooves: Composing for the sense of touch. Journal of New Music Research, 32, 369-381.

Harry, J. D., Niemi, J. B., Priplata, A. A., \& Collins, J. J. (2005). Balancing act. IEEE Spectrum, April, 36-41.

Hawkes, G. R. (1960). Symposium on cutaneous sensitivity. Medical Research Laboratories Report No. 424. Fort Knox, Kentucky.

Hein, G., \& Schubert, T. (2004). Aging and input processing in dual-task situations. Psychology and Aging, 19, 416-432.

Hennessy, J. R. (1966). Cutaneous sensitivity communications. Human Factors, 8, 463-469.

Hillstrom, A. P., Shapiro, K., \& Spence, C. (2002). Attentional and perceptual limitations in processing sequentially presented vibrotactile targets. Perception \& Psychophysics, 64, 1068-1082.

Hirsch, J. (1974). Rate control in man-machine systems. In F. A. Geldard (Ed.), Cutaneous communication systems as devices (pp. 65-72). Austin, TX: Psychonomic Society.

Ho, C., \& Spence, C. (2006). Verbal interface design: Do verbal directional cues automatically orient visual spatial attention? Computers in Human Behavior, 22, 733-748.

Ho, C., Tan, H. Z., \& Spence, C. (2005). Using spatial vibrotactile cues to direct a driver's visual attention. Transportation Research Part F: Traffic Psychology and Behaviour, 8, 397-412.

Ho, C., Tan, H. Z., \& Spence, C. (2006). The differential effect of vibrotactile and auditory cues on visual spatial attention. Ergonomics, 49, 724-738.

Hochberg, J. (1968). In the mind's eye. In R. M. Haber (Ed.), Contemporary theory and research in visual perception (pp. 337-354). London: Holt, Rinehart \& Winston.

Hodzic, A., Veit, R., Karim, A. A., Erb, M., \& Godde, B. (2004). Improvement and decline in tactile discrimination behaviour after cortical plasticity induced by passive tactile coactivation. Journal of Neuroscience, 24, 442-446.

Hoffman, H. G. (1998). Physically touching virtual objects using tactile augmentation enhances the realism of virtual environments. Proceedings of the IEEE Virtual Reality Annual International Symposium '98, 59-63.

Hoffman, H. G., Hollander, A., Schroder, K., Rousseau, S., \& Furness, T. (1998). Physically touching and tasting virtual objects enhances the realism of virtual environments. Virtual Reality: Research, Development, and Application, 3, 226-234.

Hopp, P. J., Smith, C. A. P., Clegg, B. A., \& Heggestad, E. D. (2005). Interruption management: The use of attention-directing tactile cues. Human Factors, 47, 1-11.

Hopp-Levine, P. J., Smith, C. A. P., Clegg, B. A., \& Heggestad, E. D. (2006). Tactile interruption management: Tactile cues as task-switching reminders. Cognition, Technology o. Work, 8, 137-145.

Howe, R. D., \& Matsuoka, Y. (1999). Robotics for surgery. Annual Reviews in Biomedical Engineering, 1, 211-240.

Iwata, H., Yano, H., \& Kawamura, R. (2002). Array force display for hardness distribution. Proceedings of the Tenth International Symposium on Haptic Interfaces for Virtual Environment and Teleoperator Systems, 165-171.

Janssen, W., \& Nilsson, L. (1993). Behavioural effects of driver support. In A. M. Parkes \& S. Franzen (Eds.), Driving future vehicles (pp. 147-155). London: Taylor \& Francis.

Janssen, W. H., \& Thomas, H. (1997). In-vehicle collision avoidance support under adverse visibility conditions. In Y. I. Noy (Ed.), Ergonomics and safety of intelligent driver interfaces (pp. 221-229). Mahwah, NJ: Erlbaum.

Jeram, G. J., \& Prasad, J. V. R. (2005). Open architecture for helicopter tactile cueing systems. Journal of the American Helicopter Society, 50, 238-248.

Jevons, W. S. (1871). The power of numerical discrimination. Nature, 3, 281-282.

Johnson, K. O., Van Boven, R. W., \& Hsaio, S. S. (1994). The perception of two points is not the spatial resolution threshold. In J. Boivie, P. Hansson, \& U. Lindblom (Eds.), Touch, temperature, and pain in health and disease: Mechanisms and assessments. Seattle: IASP Press.

Jones, L. A., Lockyer, B., \& Piateski, E. (2006). Tactile display and vibrotactile pattern recognition on the torso. Advanced Robotics, 20, 1359-1374.

Kajimoto, H., Kawakami, N., Tachi, S., \& Inami, M. (2004). SmartTouch: Electric skin to touch the untouchable. IEEE Computer Graphics and Applications, 36-42.

Karnath, H. O., Ferber, S., \& Himmelbach, M. (2001). Spa- 
tial awareness is a function of the temporal not the posterior parietal lobe. Nature, 411, 950-953.

Kaufman, E., Lord, M., Reese, T., \& Volkmann, J. (1949). The discrimination of visual number. American Journal of Psychology, 62, 498-525.

Kirman, J. H. (1973). Tactile communication of speech. Psychological Bulletin, 80, 54-74.

Kóbor, I., Füredi, L., Kovács, G., Spence, C., \& Vidnyánszky, Z. (2006). Back-to-front: Improved tactile discrimination performance in the space you can't see. Neuroscience Letters, $400,163-167$.

Kontarinis, D. A., \& Howe, R. D. (1995). Tactile display of vibratory information in teleoperation and virtual environments. Presence: Teleoperators and Virtual Environments, 4 387-402

Kume, Y., Shirai, A., Tsuda, M., \& Hatada, T. (1998). Information transmission through soles by vibro-tactile stimulation. Transactions of the Virtual Reality Society of Japan, 3, 83-88.

Kupers, R., \& Ptito, M. (2004). "Seeing” through the tongue: Cross-modal plasticity in the congenitally blind. International Congress Series (Frontiers in Human Brain Topology). Proceedings of ISBET 2004, 1270, 79-84.

Lakatos, S., \& Shepard, R. N. (1997). Time-distance relations in shifting attention between locations on one's body. Perception \& Psychophysics, 59, 557-566.

Lavie, N. (2005). Distracted and confused? Selective attention under load. Trends in Cognitive Sciences, 9, 75-82.

Lechelt, E. C. (1971). Spatial numerosity discrimination as contingent upon sensory and extrinsic factors. Perception and Psychophysics, 10(3), 180-184.

Lechelt, E. C. (1974). Pulse number discrimination in tactile spatio-temporal patterns. Perceptual \& Motor Skills, 39, $815-822$

Lechelt, E. C. (1975). Temporal numerosity discrimination: Intermodal comparisons revisited. British Journal of Psychology, 66, 101-108.

Lee, J. D., Hoffman, J. D., \& Hayes, E. (2004). Collision warning design to mitigate driver distraction. Proceedings of the SIGCHI conference on human factors in computing systems, 65-72.

Levison, W. H., Tanner, R. B., \& Triggs, T. J. (1973). Evaluation of tactual displays for flight control. In Proceedings of the Ninth Annual Conference on Manual Control, 55-70.

Lindeman, R. W., Page, R., Yanagida, Y., \& Sibert, J. L. (2004). Towards full-body haptic feedback: The design and deployment of a spatialized vibrotactile feedback system.
Proceedings of ACM Virtual Reality Software and Technology (VRST) 2004, 146-149.

Lindeman, R. W., Templeman, J. N., Sibert, J. L., \& Cutler, J. R. (2002). Handling of virtual contact in immersive virtual environments: Beyond visuals. Virtual Reality, 6, 130139.

Lindeman, R. W., Yanagida, Y., Sibert, J. L., \& Lavine, R. (2003). Effective vibrotactile cueing in a visual search task. Proceedings of the Ninth IFIP TC13 International Conference on Human-Computer Interaction (INTERACT 2003), 89-96.

Linvill, J. G., \& Bliss, J. C. (1966). A direct translation reading aid for the blind. Proceedings of the Institute of Electrical and Electronics Engineers, 54, 40-51.

Mahar, D., Mackenzie, B., \& McNicol, D. (1994). Modalityspecific differences in the processing of spatially, temporally, and spatiotemporally distributed information. Perception, 23, 1369-1386.

Marks, P. (2006). Gadgets get the feel of the tactile world. New Scientist, 2560, 27.

Martin, M. (1980). Attention to words in different modalities: Four-channel presentation with physical and semantic selection. Acta Psychologica, 44, 99-115.

McGehee, D. V., \& Raby, M. (2003). The design and evaluation of snowplow lane awareness system (HF-PPC 2003-1). Iowa City, IA: University of Iowa Public Policy Center.

McGehee, D. V., Raby, M., Lee, J. D., \& Nourse, G. E. (2001). Final design and operating characteristics of a snowplow lane awareness system. Paper presented at the 80th Annual Meeting of the Transportation Research Board. 7-11 January, Washington, DC.

Moss, F., \& Milton, J. G. (2003). Balancing the unbalanced. Nature, 425, 911-912.

Murray, A., Klatzky, R. L., \& Khosla, P. (2003). Psychophysical characterization and testbed validation of a wearable vibrotactile glove for telemanipulation. Presence: Teleoperators and Virtual Environments, 12, 156-182.

Nagel, S. K., Carl, C., Kringe, T., Martin, R., \& Konig, P. (2005). Beyond sensory substitution-Learning the sixth sense. Journal of Neural Engineering, 2, R13-R26.

Nakamura, A., Yamada, T., Goto, A., Kato, T., Ito, K., Abe, Y., et al. (1998). Somatosensory homunculus as drawn by MEG. Neuroimage, 74, 377-386.

Narici, L., Modena, I., Opsomer, R. J., Pizzella, V., Romani, G. L., Torrioli, G., et al. (1991). Neuromagnetic somatosensory homunculus: A non-invasive approach in humans. Neuroscience Letters, 121, 51-54. 
Okamura, A. M., Cutkosky, M. R., \& Dennerlein, J. T. (2001). Reality-based models for vibration feedback in virtual environments. IEEE/ASME Transactions on Mechatronics, 6, 245-252.

Pashler, H. (1988). Familiarity and visual change detection. Perception and Psychophysics, 44, 369-378.

Pawluk, D. T. V., Buskirk, C. P. v., Killebrew, J. H., Hsiao, S. S., \& Johnson, K. O. (1998). Control and pattern specification for a high density tactile array. Proceedings of the Seventh International Symposium on Haptic Interfaces for Virtual Environment and Teleoperator Systems, 97102.

Penfield, W., \& Boldrey, E. (1937). Somatic motor and sensory representation in the cerebral cortex of man as studied by electrical stimulation. Brain, 60, 389-443.

Posey, T. B., \& James, M. R. (1976). Numerosity discrimination of tactile stimuli. Perceptual and Motor Skills, 42, 671674.

Priplata, A. A., Niemi, J. B., Harry, J. D., Lipsitz, L. A., \& Collins, J. J. (2003). Vibrating insoles and balance control in elderly people. The Lancet, 362, 1123-1124.

Recanzone, G. H., Jenkins, W. M., Hradek, G. T., \& Merzenich, M. M. (1992). Progressive improvement in discriminative abilities in adult owl monkeys performing a tactile frequency discrimination task. Journal of Neurophysiology, 67, 1015-1030.

Rensink, R. A. (2000). Seeing, sensing, and scrutinizing. Vision Research, 40, 1469-1487.

Rensink, R. A. (2002). Change detection. Annual Review of Psychology, 53, 245-277.

Riggs, K. J., Ferrand, L., Lancelin, D., Fryziel, L., Dumur, G., \& Simpson, A. (2006). Subitizing in tactile perception. Psychological Science, 17, 271-275.

Rupert, A. H. (2000). An instrumentation solution for reducing spatial disorientation mishaps. IEEE Engineering in Medicine and Biology, 19, 71-80.

Rupert, A. H., Guedry, F. E., \& Reschke, M. F. (1994). The use of tactile interfaces to convey position and motion perceptions. Advisory Group for Aerospace Research and Development CP541, 20-1-20-7.

Saltzman, I., \& Garner, W. (1948). Reaction time as a measure of the span of attention. Journal of Psychology, 25, 227241.

Sampaio, E., Maris, S., \& Bach-y-Rita, P. (2001). Brain plasticity: "Visual" acuity of blind persons via the tongue. Brain Research, 908, 204.
Sanders, M. S., \& McCormick, E. J. (1987). Human factors in engineering and design (6th ed.). New York: McGrawHill.

Saunders, F. A., Hill, W. A., \& Franklin, B. (1981). A wearable tactile sensory aid for profoundly deaf children. Journal of Medical Systems, 5, 265-270.

Schimirgk, K., \& Rüttinger, H. (1980). The touch corpuscles of plantar surface of the big toe. Histological and histometrical investigations with respect to age. European Neurology, 19, 49-60.

Schotz, D. A. (1958). Fundamental principles of form perception in touch. Acta Psychologica, 13, 299-333.

Schumann, J., Godthelp, H., Farber, B., \& Wontorra, H. (1993). Breaking up open-loop steering control actions: The steering wheel as an active control device. In A. G. Gale, I. D. Brown, C. M. Haslegrave, H. W. Kruysse, \& S. P. Taylor (Eds.), Vision in vehicles-IV (pp. 321-332). Amsterdam: Elsevier Science.

Segond, H., \& Weiss, D. (2005). Human spatial navigation via a visuo-tactile sensory substitution system. Perception, 34, 1231-1249.

Sekuler, R., \& Blake, R. (1987). Sensory underload. Psychology Today, 12, 48-51

Senders, J. W., Kristofferson, A. B., Levison, W. H., Dietrich, C. W., \& Ward, J. L. (1967). The attentional demand of automobile driving. Highway Research Record, 195, 15-33.

Sherrick, C. E. (1985). Touch as a communicative sense: Introduction. Journal of the Acoustical Society of America, 77, $218-219$.

Sivak, M. (1996). The information that drivers use: Is it indeed 90\% visual? Perception, 25, 1081-1089.

Sklar, A. E., \& Sarter, N. B. (1999). Good vibrations: Tactile feedback in support of attention allocation and humanautomation coordination in event-driven domains. Human Factors, 41, 543-552.

Smith, G. (2004). Good vibrations. The Guardian, November 2. Available at http://www.guardian.co.uk/wheels/story/ 0,3605,1341281,00.html.

Sorkin, R. D. (1987). Design of auditory and tactile displays. In G. Salvendy (Ed.), Handbook of human factors (pp. 549 576). New York: Wiley.

Soto-Faraco, S., \& Spence, C. (2002). Modality-specific auditory and visual temporal processing deficits. Quarterly Journal of Experimental Psychology (A), 55, 23-40.

Spence, C. (2002). Multimodal attention and tactile information processing. Behavioral Brain Research, 135, 57-64. 
Spence, C., \& Driver, J. (1997). Cross-modal links in attention between audition, vision, and touch: Implications for interface design. International Journal of Cognitive Ergonomics, 1, 351-373.

Spence, C., \& Driver, J. (Eds.). (2004). Crossmodal space and crossmodal attention. Oxford, UK: Oxford University Press.

Spence, C., Nicholls, M. E. R., \& Driver, J. (2001). The cost of expecting events in the wrong sensory modality. Perception and Psychophysics, 63, 330-336.

Spence, C., Shore, D. I., \& Klein, R. M. (2001). Multisensory prior entry. Journal of Experimental Psychology: General, 130, 799-832.

Stevens, J. C., \& Choo, K. K. (1996). Spatial acuity of the body surface over the life span. Somatosensory and Motor Research, 13, 153-166.

Summers, I. R., \& Chanter, C. M. (2002). A broadband tactile array on the fingertip. Journal of the Acoustical Society of America, 112, 2118-2126.

Summers, I. R., Whybrow, J. J., Gratton, D. A., Milnes, P., Brown, B. H., \& Stevens, J. C. (2005). Tactile information transfer: A comparison of two stimulation sites. Journal of the Acoustical Society of America, 118, 2527-2534.

Talland, G. A. (1964). The effect of warning signals on reaction time in youth and old age. Journal of Gerontology, 19, 31-38.

Tan, H. Z., Gray, R., Young, J. J., \& Traylor, R. (2003). A haptic back display for attentional and directional cueing. Haptics-e: The Electronic Journal of Haptics Research, 3, 20. Available at http://www.haptics-e.org.

Tan, H. Z., \& Pentland, A. (2001). Tactual displays for sensory substitution and wearable computers. In W. Barfield \& T. Caudell (Eds.), Fundamentals of wearable computers and augmented reality (pp. 579-598).

Tang, H., \& Beebe, D. J. (2003). An oral tactile interface for blind navigation. IEEE Transactions on Neural Systems and Rehabilitation Engineering, 14, 116-123.

Thomas, R., Press, C., \& Haggard, P. (2006). Shared representations in body perception. Acta Psychologica, 121, 317330 .

Trick, L. M., \& Pylyshyn, Z. W. (1993). What enumeration studies can show us about spatial attention: Evidence for limited capacity preattentive processing. Journal of Experimental Psychology: Human Perception and Performance, 12, 331-351.

Triggs, T. J., Lewison, W. H., \& Sanneman, R. (1974). Some experiments with flight-related electrocutaneous and vibrotactile displays. In F. A. Geldard (Ed.), Cutaneous commu- nication systems as devices (pp. 57-64). Austin, TX: Psychonomic Society.

Vallar, G. (2001). Extra-personal visual unilateral spatial neglect and its neuroanatomy. NeuroImage, 14, S52-S58.

Van Erp, J. B. F. (2000). Tactile navigation display. Haptic Human-Computer Interaction 2000, 165-173.

Van Erp, J. B. F. (2005). Presenting directions with a vibrotactile torso display. Ergonomics, 48, 302-313.

Van Erp, J. B. F., \& Van Veen, H. A. H. C. (2003). A multipurpose tactile vest for astronauts in the international space station. In Proceedings of Eurohaptics 2003 (pp. 405-408). Dublin, Ireland: Trinity College.

Van Erp, J. B. F., \& Van Veen, H. A. H. C. (2004). Vibrotactile in-vehicle navigation system. Transportation Research Part F: Traffic Psychology and Behaviour, 7, 247-256.

Van Erp, J. B. F., Van Veen, H. A. H. C., Jansen, C., \& Dobbins, T. (2005). Waypoint navigation with a vibrotactile waist belt. ACM Transactions on Applied Perception, 2, 106-117.

Van Veen, H. A. H. C., \& Van Erp, J. B. F. (2000). Tactile information presentation in the cockpit. Haptic HumanComputer Interaction 2000, 174-181.

Velichkovsky, B. M., Dornhoefer, S. M., Kopf, M., Helmert, J., \& Joos, M. (2002). Change detection and occlusion modes in road-traffic scenarios. Transportation Research Part F: Traffic Psychology and Behaviour, 5, 99-109.

Verrillo, R. T., and Chamberlain, S. C. (1972). The effect of neural density and contactor surround on vibrotactile sensation magnitude. Perception and Psychophysics, 11, 117-120.

Verrillo, R. T., \& Gescheider, G. A. (1992). Perception via the sense of touch. In I. R. Summers (Ed.), Tactile aids for the hearing impaired (pp. 1-36). London: Whurr Publishers.

Vitense, H. S., Jacko, J. A., \& Emery, V. K. (2003). Multimodal feedback: An assessment of performance and mental workload. Ergonomics, 46, 68-87.

Von Haller Gilmer, B. (1960). Possibilities of cutaneous electro-pulse communication. In G. R. Hawkes (Ed.), Symposium on cutaneous sensitivity (pp. 76-84). USA Med. Res. Lab. Report No. 424.

Von Haller Gilmer, B. (1961). Toward cutaneous electropulse communication. Journal of Psychology, 52, 211-222.

Weinstein, S. (1968). Intensive and extensive aspects of tactile sensitivity as a function of body part, sex, and laterality. In D. R. Kenshalo (Ed.), The skin senses (pp. 195-222). Springfield, IL: Thomas.

Weisenberger, J. M., \& Miller, J. D. (1987). The role of tac- 
tile aids in providing information about acoustic stimuli. Journal of the Acoustical Society of America, 82, 906-916.

Weiss, W. (1965). Influence of an irrelevant stimulus attribute on numerosity judgments. Perceptual and Motor Skills, 21, 404.

White, B. W., Saunders, F. A., Scadden, L., Bach-Y-Rita, P., \& Collins, C. C. (1970). Seeing with the skin. Perception \& Psychophysics, 7, 23-27.

Wickens, C. D. (1980). The structure of attentional resources. In R. Nickerson \& R. Pew (Eds.), Attention and performance VIII (pp. 239-257). Hillsdale, NJ: Erlbaum.

Wilkins, P. A., \& Acton, W. I. (1982). Noise and accidentsA review. Annals of Occupational Hygiene, 25, 249-260.
Wright, M., Green, A., \& Baker, S. (2000). Limitations for change detection in multiple Gabor targets. Visual Cognition, 7, 237-252.

Yano, H., Ogi, T., \& Hirose, M. (1998). Development of haptic suit for whole human body using vibrators. Transactions of the Virtual Reality Society of Japan, 3(3), 141-148.

Yuan, H., Reed, C. M., \& Durlach, N. I. (2003). Tactual displays of consonant voicing to supplement speechreading. Journal of the Acoustic Society of America, 113, 2291 (A).

Yuan, H., Reed, C. M., \& Durlach, N. I. (2005). Tactual display of consonant voicing to supplement lipreading. Journal of the Acoustical Society of America, 118, 1003-1015. 